\title{
Modelling diffuse instabilities in sands under drained conditions
}

\author{
A. M. RAMOS*, J. E. ANDRADE $\uparrow$ and A. LIZCANO
}

\begin{abstract}
This paper presents a criterion for detecting diffuse (homogeneous) instabilities in granular soils sheared under fully drained conditions. The criterion is based on bifurcation theory and applied to elasto-plasticity by allowing multiple incremental solutions in elasto-plastic soils, physically losing controllability of stress boundary conditions. Drained diffuse instabilities are poorly understood, and are induced by kinematic modes different from those observed in shear bands and liquefaction instabilities. Unlike shear bands, diffuse instabilities occur under fairly homogenous deformation modes and, unlike liquefaction, drained instabilities are not generated by the excess pore pressures. Recent experiments under drained constant shear report sudden homogeneous instabilities in samples of relatively dense and loose sands. The criterion presented in this paper is used in conjunction with an elasto-plasticity model for sands to predict and explain these reported drained instabilities. From a practical standpoint, these developments serve to expand the repertoire of potential instabilities that occur well before failure, and which have been reported in case studies of puzzling slope instability failures under fully drained conditions.
\end{abstract}

KEYWORDS: failure; numerical modelling; plasticity; sands; theoretical analysis
Cette communication présente un critère pour la détection d'instabilités diffuses (homogènes) dans des sols granulaires cisaillés, et dans des conditions entièrement drainées. Ce critère est basé sur la théorie de la bifurcation, et appliqué à l'élastoplasticité, en permettant des solutions incrémentielles multiples dans des sols élastoplastiques - en perdant physiquement de la contrôlabilité dans des conditions limites des contraintes. Les instabilités diffuses drainées sont mal connues; elles sont induites par des modes cinématiques différents de ceux que l'on relève dans des bandes de cisaillement et des instabilités de liquéfaction. Contrairement aux bandes de cisaillement, des instabilités diffuses se produisent dans des modes de déformation homogènes, et, contrairement à la liquéfaction, des instabilités drainées ne sont pas produites sous l'effet de pressions interstitielles excessives. Des expériences menées récemment dans des conditions de cisaillement constant drainé font état d'instabilités homogènes soudaines dans des échantillons de sable relativement dense et meuble. Le critère présenté dans la présente communication est utilisé conjointement avec un modèle d'élastoplasticité pour les sables, afin de prédire et d'expliquer ces instabilités drainées signalées. D'un point de vue pratique, ces développements servent à accroître le répertoire d'instabilités potentielles survenant bien avant la rupture, et qui ont été signalées dans des études de cas présentant des instabilités de pentes intrigantes dans des conditions entièrement drainées.

\section{INTRODUCTION}

Slope stability analysis is one of the key components of geotechnical engineering practice and, as such, it is fairly well understood under the paradigms of limit state or failure analysis. However, there exist cases where slopes display unstable behaviour well before failure conditions are reached. For instance, Lade (1993) showed the existence of instabilities under undrained conditions under stress levels below failure for the submarine Nerlek berm. There have also been cases of instability under essentially drained conditions, such as the Wachusett Dam failure in 1907, and analysed by Olson et al. (2000). These and other field case studies have motivated ample research into the stability characteristics of granular materials (Lade, 1992; Nova, 1994; Darve \& Laouafa, 2000; Gajo et al., 2000; Chu et al., 2003; Borja, 2006; Andrade, 2009).

Unstable behaviour can be defined as the sudden large response of a system or material to relatively small perturbations. In the case of soils, this can be observed as the sudden large increase of shear strains as a result of a small perturbation in loading conditions, for example. From a

Manuscript received 30 September 2010; revised manuscript accepted 9 September 2011. Published online ahead of print 22 February 2012. Discussion on this paper closes on 1 November 2012; for further details see p. ii.

* Geophysical Institute, Pontificia Universidad Javeriana, Bogotá, Colombia.

$\uparrow$ California Institute of Technology, Pasadena, USA

† Universidad de Los Andes, Bogotá, Colombia. theoretical standpoint, Hill (1958) and Rudnicki \& Rice (1975) established a foundation for understanding loss of uniqueness and stability in solids. In particular, the latter improved our understanding of localisation bands, which constitute a subset of instabilities where the deformation mode is prescribed by the normal to the deformation band, and by the dilatancy of the material. Liquefaction instabilities have been studied by, among others, Lade (1992), Nova (1994), Borja (2006) and Andrade (2009), under the framework of Hill's instability condition or the second-order work (Darve \& Laouafa, 2000). The kinematical constraint for liquefaction instabilities is determined by purely undrained conditions, which translate into constant-volume deformations in the case of incompressible solid and fluid constituents (Andrade, 2009). Therefore drained instabilities, where deformations are not localised (cf. shear bands) and volume is not preserved (cf. liquefaction), must be induced by different kinematics.

Experimentally, Lindenberg \& Koning (1981) were among the first to recognise unstable behaviour in loose sands under drained static conditions. Several experimental studies have been performed under constant deviatoric stress (CDS), which report sudden collapse of sandy soils under quasi-static loading and for relative densities ranging from dense to loose (Skopek et al., 1994; Gajo et al., 2000; Chu et al., 2003). A typical stress path followed in the experiments is shown in Fig. 1. Initially, samples are loaded under drained triaxial compression (path from A to B) until a certain level of deviatoric stress $q$ is reached at point B. Subsequently, a constant deviatoric stress path is imposed, effectively reducing 


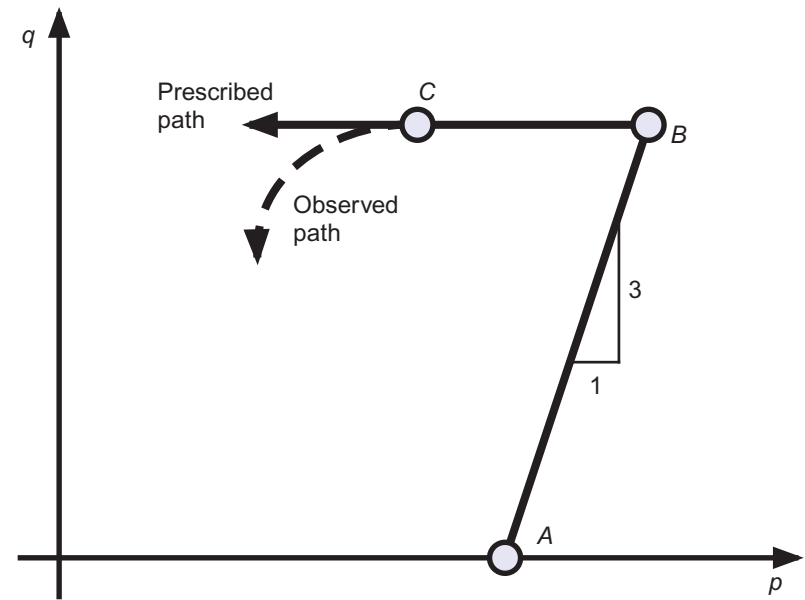

Fig. 1. Sketch of constant deviatoric stress (CDS) experiments. Samples are initially sheared under drained triaxial compression (from A to B), and subsequently to a constant deviatoric path of decreasing normal pressure (from B to C). Suddenly, certain samples develop an instability, and loss of controllability of constant deviatoric stress is experienced

the mean stress $p$ at constant rate. Suddenly, the sample experiences an instability, represented by point $\mathrm{C}$ in the figure. After point $\mathrm{C}$, the sample is unable to follow the prescribed stress trajectory, experiencing loss of controllability (Nova, 1994). In their experimental study, Chu et al. (2003) reported loss of controllability (to impose constant $q$ ) and a sudden large increase in strains. These instabilities occur under drained conditions, without the apparent presence of shear bands; in fact the samples appear fairly homogeneous up to the onset of instability. Further, Gajo et al. (2000) and Chu et al. (2003) reported instabilities under CDS conditions that were well above the so-called instability line (Lade \& Pradel, 1990; Vaid \& Chern, 1983). CDS paths are believed to model a decrease in mean effective pressure in slopes due to a slow increase in pore pressures caused by rainfall infiltration, or under submerged conditions.

Aiming at understanding instabilities occurring under drained conditions in the field, the objective in the current work is to model and predict instabilities under drained conditions at a material level. In this paper, a simple instability criterion is proposed, based on Hill's instability condition, and is applied to elasto-plasticity to explain and predict the drained diffuse instabilities observed in the aforementioned CDS experiments. To this end, the paper aims at shedding some light on two fundamental questions.

(a) Is it possible to explain and predict drained diffuse instabilities in the context of CDS experiments using mathematical models?

(b) What are the mechanics governing drained diffuse instabilities, and how do these relate to shear banding and liquefaction?

To start answering these questions, the Chu et al. (2003) experiments are used as a test bed, and the Manzari \& Dafalias (1997) plasticity model is used, with the latest enhancements (Dafalias \& Manzari, 2004), to simulate the behaviour of sands accurately under loose and dense conditions. Furthermore, the instability criterion for loss of controllability under drained conditions is carefully derived, and contrasted with those associated with shear banding and static liquefaction.

The structure of the paper is as follows. The next section, 'Drained instability criterion', derives the instability criterion under the special case of triaxial loading, for the sake of simplicity. The section 'Constitutive model' describes the
Manzari-Dafalias model, for completeness of presentation. Numerical calculations are presented in the 'Numerical predictions' section, and these results are compared with the experiments performed by $\mathrm{Chu}$ et al. (2003). The numerical predictions are followed by a discussion section. Finally, the paper is closed in the conclusions section, highlighting the main findings.

\section{DRAINED INSTABILITY CRITERION}

Without loss of generality, and for the sake of simplicity, the discussion is limited to axisymmetric conditions, equivalent to those encountered in classic 'triaxial' experiments. All findings pertaining to this section can be shown to hold for general loading conditions using tensor analysis.

Consider a classic elasto-plastic model with a yield surface $F=F(p, q)$ as a function of the two stress invariants $p=\frac{1}{3}\left(\sigma_{\mathrm{a}}+2 \sigma_{\mathrm{r}}\right)$ and $q=\sigma_{\mathrm{a}}-\sigma_{\mathrm{r}}$, where $\sigma_{\mathrm{a}}$ and $\sigma_{\mathrm{r}}$ are the axial and radial components of the stress, respectively. Similarly, a plastic potential function $Q=Q(p, q)$ is considered, which defines the direction of the plastic strains such that

$$
\varepsilon_{\mathrm{v}}^{\mathrm{p}}=\dot{\lambda} \frac{\partial Q}{\partial p} ; \dot{\varepsilon}_{\mathrm{s}}^{\mathrm{p}}=\dot{\lambda} \frac{\partial Q}{\partial q}
$$

with $\dot{\lambda}$ as the plastic multiplier, measuring the magnitude of plastic strain increments. Assuming additive decomposition of total strains into elastic and plastic components, then $\dot{\varepsilon}_{\mathrm{v}}=\dot{\varepsilon}_{\mathrm{v}}^{\mathrm{e}}+\dot{\varepsilon}_{\mathrm{v}}^{\mathrm{p}}$ and $\dot{\varepsilon}_{\mathrm{s}}=\dot{\varepsilon}_{\mathrm{s}}^{\mathrm{e}}+\dot{\varepsilon}_{\mathrm{s}}^{\mathrm{p}}$, where the subscripts $\mathrm{v}$ and $\mathrm{s}$ stand for 'volumetric' and 'deviatoric' respectively. The invariants of the strain rate are defined as usual as $\dot{\varepsilon}_{\mathrm{v}}=\dot{\varepsilon}_{\mathrm{a}}+2 \dot{\varepsilon}_{\mathrm{r}}$ and $\dot{\varepsilon}_{\mathrm{s}}=\frac{2}{3}\left(\dot{\varepsilon}_{\mathrm{a}}+2 \dot{\varepsilon}_{\mathrm{r}}\right)$

The stress increments are related to the elastic portion of the deformation increment in the usual way, by

$$
\dot{p}=K \dot{\varepsilon}_{\mathrm{v}}^{\mathrm{e}} ; \dot{q}=3 G \dot{\varepsilon}_{\mathrm{s}}^{\mathrm{e}}
$$

with $K$ and $G$ as the bulk and shear moduli of the soil. Exploiting the additive decomposition of the strain rates and the consistency condition, requiring $\dot{F}=0$, it is possible to relate the stress increments to the total strain increments such that

$$
\underbrace{\left\{\begin{array}{c}
\dot{p} \\
\dot{q}
\end{array}\right\}}_{\dot{\sigma}}=\underbrace{\left[\begin{array}{cc}
K-\frac{1}{\chi} K^{2} \partial_{p} F \partial_{p} Q & -\frac{3}{\chi} K G \partial_{q} F \partial_{p} Q \\
-\frac{3}{\chi} K G \partial_{p} F \partial_{q} Q & 3 G-\frac{9}{\chi} G^{2} \partial_{q} F \partial_{q} Q
\end{array}\right]}_{c} \underbrace{\left\{\begin{array}{c}
\dot{\varepsilon}_{\mathrm{v}} \\
\dot{\varepsilon}_{\mathrm{s}}
\end{array}\right\}}_{\dot{\varepsilon}}
$$

with $\chi=H+K \partial_{p} F \partial_{p} Q+3 G \partial_{q} F \partial_{q} Q$ and $H$ as the hardening modulus, which controls the evolution of the internal plastic variables in the model. Equation (3) furnishes the classic constitutive relation between the stress increment $\dot{\sigma}$ and the strain increment $\dot{\varepsilon}$ by way of the constitutive tangent $c$. The determinant function of the constitutive tangent is given by

$$
\operatorname{det} c=\frac{3}{\chi} K G H
$$

Under stress-controlled conditions, the left-hand side of equation (3) is prescribed. For example, under CDS paths, $\dot{q}=0$ and $\dot{p}=$ const $>0$ is prescribed. Loss of controllability (Nova, 1994), under stress conditions, is achieved when $\operatorname{det} \boldsymbol{c}=0$. In this case, loss of controllability (Imposimato \& Nova, 1998) can be shown to be the same condition for loss of uniqueness/stability in the sense of Hill (1958). For an elasto-plastic model, such as the one presented above, this condition coincides with 


$$
H=0 \rightarrow \operatorname{det} c=0
$$

Since the hardening modulus is typically a continuous function that is positive at the outset of loading, $H=0$ marks the transition from hardening to softening or perfect plasticity. Furthermore, when $H=0$, the condition $\dot{\sigma}=0$ is achieved with an eigenvector (strain rate) of the form

$$
\left\{\begin{array}{c}
\dot{\varepsilon}_{\mathrm{v}} \\
\dot{\varepsilon}_{\mathrm{s}}
\end{array}\right\}=\left\{\begin{array}{c}
\dot{\alpha} \partial_{p} Q \\
\dot{\alpha} \partial_{q} Q
\end{array}\right\}
$$

where $\dot{\alpha}$ is an arbitrary scalar. The physical significance of the above developments is that, at the onset of instability signalled by $H=0$, arbitrary strain increments in the direction of the plastic strain increments can be achieved, (cf. equation (6)) and, as a consequence, loss of controllability in the stress increments is observed. These theoretical observations can be applied to the experiments performed under CDS, where sudden and large increments of strains are observed, and the stress conditions cannot be controlled. Remark 1. From the developments presented above, it is possible to contrast drained diffuse instabilities with static liquefaction and strain localisation. The first difference is the onset of instability. In the case of drained diffuse instability, the onset is $H=0$, whereas for strain localisation under triaxial compression, Rudnicki \& Rice (1975) derived a localisation criterion such that $H=H_{\mathrm{sb}} \neq 0$, in general. Static liquefaction, which is a diffuse instability under undrained conditions, has an instability criterion $H=H_{\mathrm{L}}<0$, in general (Andrade, 2009). However, it is possible for these criteria to coincide under unique circumstances. Perhaps the clearest difference is the kinematic conditions. In contrast to the eigenvector shown in equation (6), static liquefaction occurs under undrained conditions, which implies $\dot{\varepsilon}_{\mathrm{v}}=0$ for incompressible constituents. On the other hand, shear bands are constrained to deformations imposed by the normal to the shear band and the dilatancy angle.

In the following section, a particular elasto-plastic model is presented to describe the behaviour of sandy soils, such as those utilised in Chu et al. (2003). The constitutive model is amenable to the instability analysis presented above, and will be used to predict instabilities observed in the laboratory.

\section{CONSTITUTIVE MODEL}

This section briefly describes the Manzari \& Dafalias (1997) model, with its recent modifications (Dafalias \& Manzari, 2004) aimed at accounting for changes in fabric that ultimately could affect dilatancy. A simplified version is presented, applicable to triaxial loading, without load reversals. For a more complete description of the model, interested readers are referred to the original papers cited above.

The constitutive model is framed in the critical state soil mechanics concept (Schofield \& Wroth, 1968), and the elastic response is hypoelastic. The shear and bulk moduli are give such that

$$
G=G_{0} p_{\mathrm{at}} \frac{(2 \cdot 97-e)^{2}}{1+e}\left(\frac{p}{p_{\mathrm{at}}}\right)^{1 / 2} \text { and } K=\frac{2(1+v)}{3(1-2 v)} G
$$

where $G_{0}$ is a constant, $v$ is Poisson's ratio, $e$ is the current void ratio and $p_{\text {at }}$ is the atmospheric pressure. The elastic region is enclosed by a yield surface in stress space, defining a wedge

$$
F(\eta, \alpha)=|\eta-\alpha|-m
$$

with $\eta=q / p$ as the stress ratio, $\alpha$ as the back stress and $m$ as a constant defining the width of the wedge, so that in $p-$ $q$ space the wedge has an opening of $2 \mathrm{mp}$ at any value $p$. Fig. 2 shows the geometrical attributes of the model in stress space. The inclination of the wedge defining the elastic region is given by the back stress, the evolution of which is governed by a kinematic hardening law

$$
\dot{\alpha}=H \dot{\varepsilon}_{\mathrm{s}}^{\mathrm{p}}
$$

where $H$ is the hardening modulus.

Under axisymmetric conditions, without stress reversals, the plastic strain directions take the following simple form (cf. equation (1)): $\partial Q / \partial p=\beta$ and $\partial Q / \partial q=1$. Hence the ratio of volumetric to deviatoric plastic deformations is weighted by the dilatancy $\beta$ of the material, such that $\dot{\varepsilon}_{\mathrm{v}}^{\mathrm{p}}=\beta \dot{\varepsilon}_{\mathrm{s}}^{\mathrm{p}}=\beta \dot{\lambda}$. In order to complete the constitutive description, it remains to explicate the evolution of the hardening modulus $H$ and the dilatancy $\beta$.

The hardening modulus is a function of the state of the material, and its sign is controlled by the relative distance to the so-called bounding stress: that is

$$
H=h\left(M^{\mathrm{b}}-\eta\right) \text { with } h=\frac{G_{0} h_{0}\left(1-c_{\mathrm{h}} e\right)}{\left|\eta-\eta_{\text {in }}\right|}\left(\frac{p}{p_{\mathrm{at}}}\right)^{-1 / 2}
$$

where $h$ is a positive function, $M^{\mathrm{b}}$ is the bounding stress ratio and $h_{0}$ and $c_{\mathrm{h}}$ are positive constants. The evolution of the dilatancy $\beta$ is given by a function similar to that of the hardening modulus, with the sign of the function dictated by the distance to the dilatancy stress, so that

$$
\beta=A_{\mathrm{d}}\left(M^{\mathrm{d}}-\eta\right)
$$

with $M^{\mathrm{d}}$ as the dilatancy stress ratio, as shown in Fig. 2. If $\eta$ is less than the value of $M^{\mathrm{d}}$, a contractive response is obtained; otherwise the model predicts dilation. The positive scaling function for the dilatancy is affected by changes in fabric such that

$$
A_{\mathrm{d}}=A_{0}(1+\langle s z\rangle) \text { with } \dot{z}=-c_{z}\left\langle-\dot{\varepsilon}_{\mathrm{v}}^{\mathrm{p}}\right\rangle\left(s z_{\max }+z\right)
$$

where $A_{0}$ is a positive constant and $s= \pm 1$ according to $\eta=\alpha \pm m$. The brackets \langle\rangle are the Macaulay brackets, representing a ramp function. Additionally, $z_{\max }$ represents the maximum value the state parameter $z$ can take.

The model is made to comply with critical state soil mechanics by postulating exponential evolution equations for the bounding and dilatancy stress ratios respectively

$$
M^{\mathrm{b}}=M \exp \left(-n^{\mathrm{b}} \psi\right) \text { and } M^{\mathrm{d}}=M \exp \left(n^{\mathrm{d}} \psi\right)
$$

with $n^{\mathrm{b}}$ and $n^{\mathrm{d}}$ as positive constants. Conceptually, the evolution equations shown above require that $M^{\mathrm{b}}$ and $M^{\mathrm{d}}$

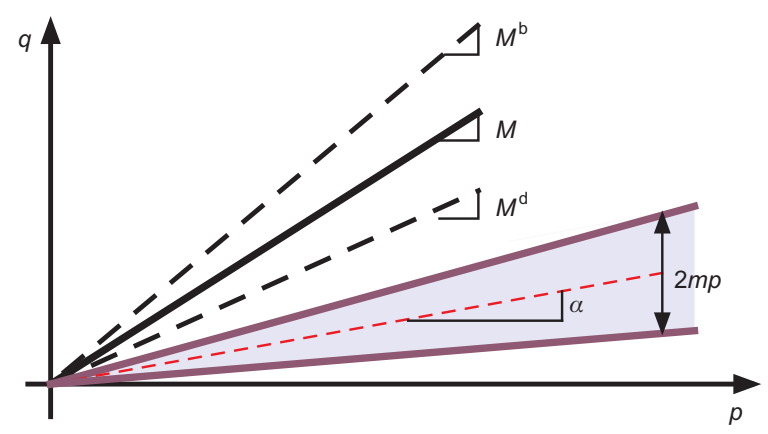

Fig. 2. Schematic of yield surface and main ingredients plotted in stress space. Shaded area represents elastic region, with inclination dictated by $\alpha$. Other important ingredients are the bounding stress ratio $M^{\mathbf{b}}$, dilatancy stress ratio $M^{\mathrm{d}}$ and critical state ratio $M$ 
coincide with $M$ as $\psi \rightarrow 0$, requiring the state to tend to critical state. The state parameter $\psi=e-e_{\mathrm{c}}$ was defined by Been \& Jefferies (1985), and measures the distance to the critical state from the current state in void ratio space. Finally, the critical state line (CSL) is defined in void ratio space according to the relationship proposed by Li \& Wang (1998)

$$
e_{\mathrm{c}}=e_{\mathrm{c} 0}-\lambda_{\mathrm{c}}\left(\frac{p_{\mathrm{c}}}{p_{\mathrm{at}}}\right)^{\xi}
$$

with $e_{\mathrm{c} 0}$ as the void ratio at $p_{\mathrm{c}}=0$, and $\lambda_{\mathrm{c}}$ and $\xi$ as constants. An example of the CSL given by this expression is shown in Fig. 6 for Changi sand. A list of material parameters for the constitutive model is given in Table 1 with reference values for Changi sand.

Remark 2. It is important to note the role of the constitutive model at this point. The criterion for diffuse instability presented earlier does not depend on a particular constitutive model. In fact, it is applicable to any constitutive model based on elasto-plasticity, and this would fit the general framework presented earlier. There are numerous constitutive models for sands available in the literature (e.g. Jefferies, 1993; Andrade \& Borja, 2006; Andrade \& Ellison, 2008). However, in this paper the Dafalias \& Manzari (2004) model is selected for its versatility in capturing CDS paths, which will be simulated in the following section. Ultimately, even though the criterion is independent of the constitutive model, the accuracy of the predictions is intimately related to the accuracy of the constitutive model used.

\section{NUMERICAL PREDICTIONS}

This section presents numerical predictions using the constitutive model presented above and the instability criterion introduced in equation (5). These predictions are compared with experimental results obtained by $\mathrm{Chu}$ et al. (2003), where constant deviatoric stress (CDS) paths were imposed on relatively dense and relatively loose samples of sand. Changi sand was used in the experimental programmes to study the stability conditions under drained and undrained situations in reclaimed land in Singapore (Chu et al., 2003; Wanatowski \& Chu, 2007; Chu \& Wanatowski, 2008). The constitutive model was calibrated using classic triaxial compression tests performed by Wanatowski \& Chu (2007). The resulting material parameters are shown in Table 1 . The material parameters, calibrated under drained triaxial compression, are held fixed during the CDS simulations, furnishing true numerical predictions.

Table 1. Material parameters for Manzari-Dafalias model for Changi sand

\begin{tabular}{l|c|c}
\hline & Constant & Changi sand \\
\hline Elasticity & $G_{0}$ & 125 \\
Critical state & $v$ & $0 \cdot 05$ \\
& $M$ & $1 \cdot 35$ \\
& $\lambda_{\mathrm{c}}$ & $0 \cdot 0919$ \\
& $e_{\mathrm{c} 0}$ & $0 \cdot 963$ \\
Yield surface & $\xi$ & $0 \cdot 4$ \\
Plastic modulus & $m$ & $0 \cdot 05$ \\
& $h_{0}$ & 5 \\
Dilatancy & $c_{\mathrm{h}}$ & $0 \cdot 8$ \\
& $n^{\mathrm{b}}$ & $1 \cdot 1$ \\
Dilatancy: fabric & $A_{0}$ & $1 \cdot 54$ \\
& $n^{\mathrm{d}}$ & $3 \cdot 5$ \\
& $z_{\max }$ & 4 \\
\hline
\end{tabular}

\section{Instability predictions in dilative sand}

Two samples of relatively dense sand were tested by Chu et al. (2003). The experimental responses for the two samples loaded under CDS conditions are shown in Figs 3 and 4 . The initial void ratio for the sample shown in Fig. 3 was $e_{0} \approx 0.66$, and for the one shown in Fig. $4, e_{0} \approx 0.65$. As shown in Figs 3(a) and 4(a), both samples were initially consolidated isotropically to a cell pressure of $150 \mathrm{kPa}$ (point A). Subsequently, the samples were sheared under drained triaxial compression (to point B). From the experimental results shown in Figs 3(b), 3(c), 4(b) and 4(c), it can be seen that the strains are small between loading stations $\mathrm{A}$ and $\mathrm{B}$ (during the triaxial compression phase).

After the triaxial compression phase (ending at point B), the samples are sheared under CDS. This CDS path is achieved by keeping $q$ constant while slowly decreasing $p$ at a constant rate. From Figs 3(b), 3(c), 4(b) and 4(c) it can be seen that strains become significantly larger at the beginning of the CDS path, but the sample is still stable. As the samples are relatively dense, the volumetric strains are observed to be purely dilative during the CDS phase. The samples continue to deform homogeneously and under stress-controlled conditions until point $\mathrm{C}$ is reached. At this point (reached at slightly different stress states for the two samples), the samples cannot be controlled, and significantly larger shear and volumetric strains are experienced. Nevertheless, the samples did not display any appearance of shear bands and remained fairly homogeneous, with a clear dilative tendency.

Parallel to the experimental results, Figs 3 and 4 present the numerical predictions using the Dafalias \& Manzari (2004) model and the instability condition shown in equation (5). Both stress paths and strains are captured by the mechanical model remarkably well. Furthermore, Figs 3(d) and 4(d) show the evolution of the hardening modulus presented in equation (10). As described before, the onset of drained instability is flagged by $H=0$. At this instant, it is possible for a sample to observe arbitrarily large strain increments, in the direction of the plastic strain increments (cf. equation (6)). Figs 3(d) and 4(d) show the onset of $H=0$, which is marked by point $\mathrm{C}^{\prime}$ in Figs 3 and 4. Just as in the experiments, the numerical samples experienced a significant increase in strain and lost controllability. In both samples, the numerical predictions are not only capturing the stress paths and strains accurately, but actually predict the onset of instability very well. Furthermore, the instability tendency, with a clear surge in axial and volumetric strains, is very well captured by the model.

\section{Instability predictions in contractive sand}

Similar to the relatively dense samples, Chu et al. (2003) also tested a relatively loose sample of Changi sand with initial void ratio $e_{0} \approx 0 \cdot 95$. The experimental results for this sample are shown in Fig. 5. Results for the loose sample are similar to those obtained for the dense samples, with the obvious difference that this sample was contractive. As before, the sample is subjected to a drained triaxial compression stage (A to B), followed by a constant- $q$ stress path, achieved by decreasing $p$ at a constant rate. As before, strains are relatively small during the triaxial compression stage, and become more significant during the CDS path. At point $\mathrm{C}$, with mean pressure around $175 \mathrm{kPa}$, the sample is reported to become unstable. There is an inflection point at $\mathrm{C}$ in the strains, but it is not as significant as those observed in the dense samples.

Figure 5 also shows the predictions given by the constitutive model for both the stress path and the strains. The evolution of the hardening modulus is also reported. The 


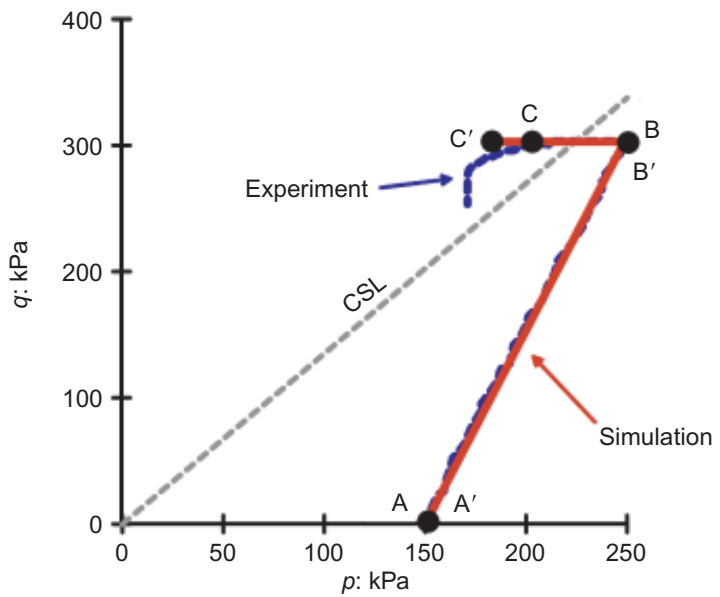

(a)

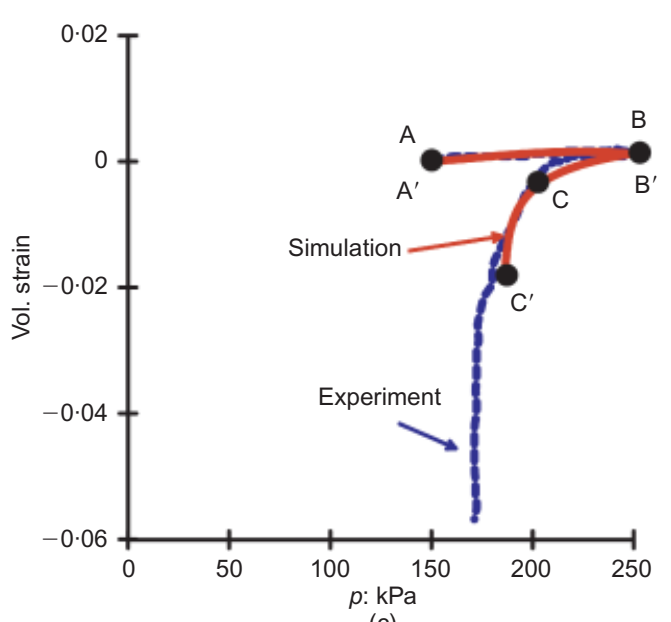

(c)

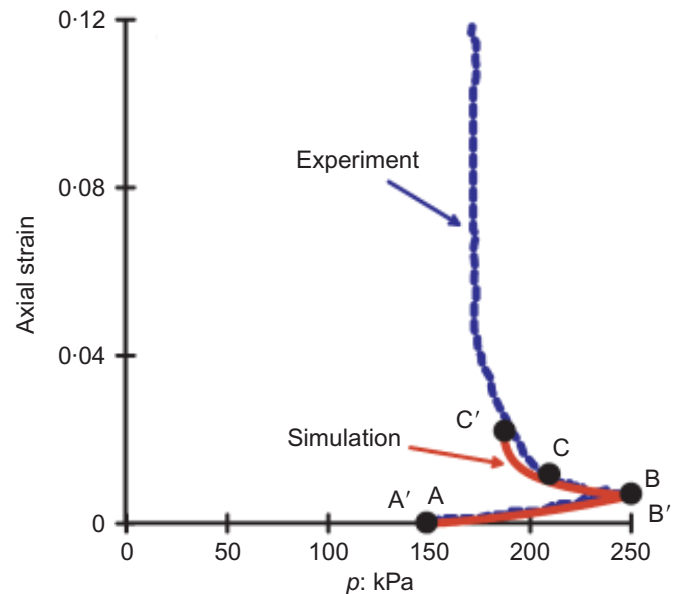

(b)

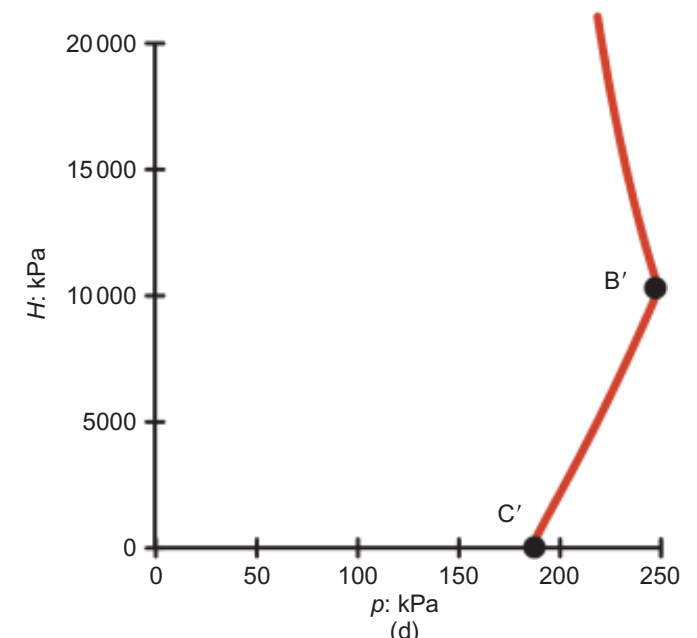

(d)

Fig. 3. Experimental and numerical results for relatively dense sample with $e_{0} \approx 0 \cdot 66$. (a) Stress path marking transition from triaxial compression (A-B) to CDS (B-C). The sample is reported to become unstable at point $\mathrm{C}$. (b) Axial strain against pressure: there is a clear inflection point at $C$. (c) Volumetric strain against pressure: there is a clear inflection point at $\mathrm{C}$. (d) Hardening modulus evolution as a function of pressure. The onset of instability is marked by $H=0$ at point $C^{\prime}$

overall tendency of the results is very good, especially considering the difficulty in capturing CDS paths using regular plasticity models. Nevertheless, the quality of the predictions is not as good as those realised for the dense samples. As before, the onset of instability is flagged in the numerical simulation by $H=0$, which is marked in Fig. 5 by point $\mathrm{C}^{\prime}$. Experimentally, the onset of instability is marked as point $\mathrm{C}$, and it can be seen that the prediction is close to that observed in the experiment, but this time the similarity is more qualitative than quantitative in nature. However, the numerical prediction captures the overall tendency of the behaviour very well, especially when one recalls the true predictive nature of this exercise.

\section{DISCUSSION}

At least three salient observations are necessary and stem naturally from this work. First, capturing CDS paths poses a significant challenge for regular elasto-plasticity models. Second, the instabilities reported herein, and all instabilities in general, occur well before failure, signified by the CSL in this model. Third, drained instabilities of the type presented herein are not associated with static liquefaction instabilities, at least not kinematically. The following discussion expands on these three observations.

As was also noted by Gajo (2004), important challenges are presented by the modelling of CDS paths using elasto- plastic constitutive models. For instance, under yielding conditions, cap models would consistently predict zero or dilative plastic strain increments shortly after point B is attained (see sketch in Fig. 1). Also, it might be possible for cap models to predict a significant elastic regime right after point B. On the other hand, models such as that of Dafalias \& Manzari (2004), equipped with kinematic hardening, can accommodate sudden switches in stress path direction, such as the one experienced at point B. Isotropic hardening can in general accommodate only monotonic loads.

Figure 6 shows the void ratio evolution for the experimental and numerical results presented in the previous section. From the figure, at least two observations can be made. First, although the three-dimensional nature of the CSL gives the impression that the material stress state lies on the CSL (Fig. 5(a)), the instability points predicted by the model and signalled by $\mathrm{C}^{\prime}$, occur well before reaching the CSL or failure. This coincides with the observation that instability is not synonymous with failure (Lade, 1992). In fact, instability is a precursor of failure. This is true not only for the drained instabilities presented in this paper, but also for others, such as static liquefaction (Lade, 1992; Andrade, 2009) and shear banding (Andrade \& Borja, 2006; Ramos \& Lizcano, 2010). The second observation stemming from Fig. 6 is the model's difficulty in capturing the appropriate amount of dilatancy mobilised by the sand. The loose sample contracts excessively, whereas the dense samples dilate too little. However, 


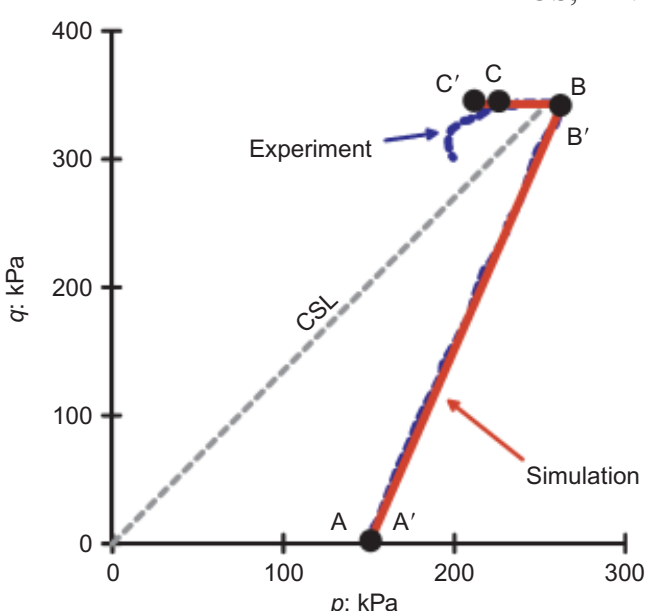

(a)

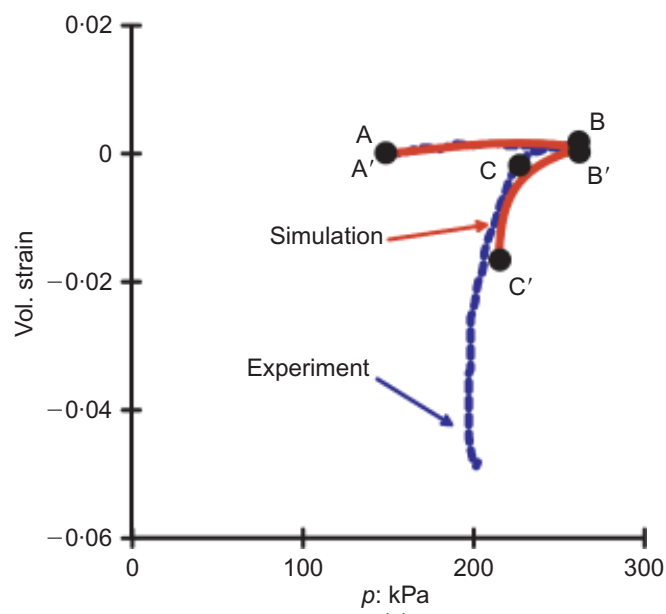

(c)

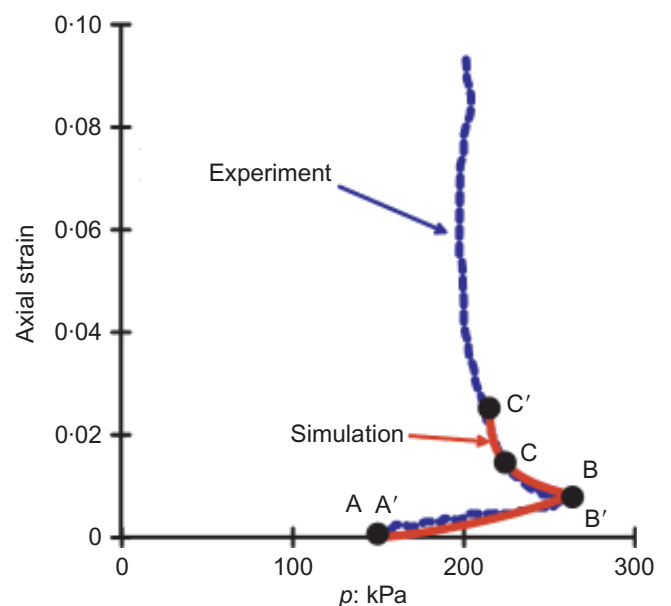

(b)

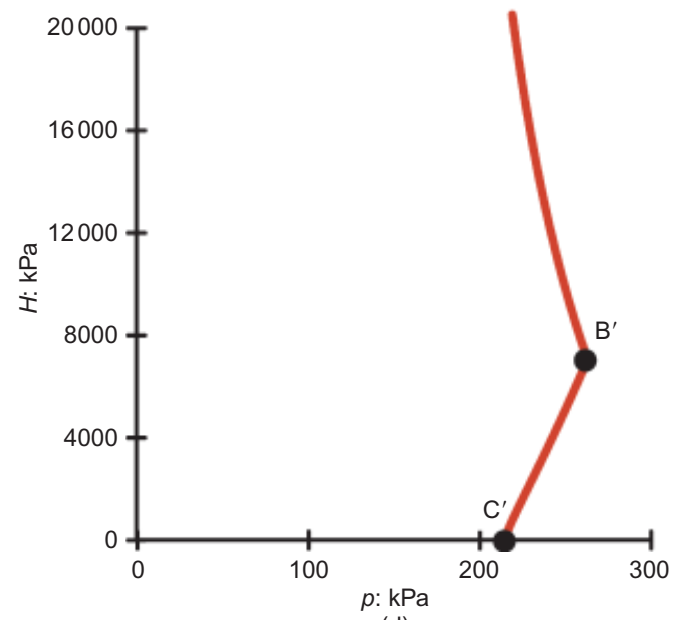

(d)

Fig. 4. Experimental and numerical results for relatively dense sample with $e_{0} \approx 0 \cdot 65$. (a) Stress path marking transition from triaxial compression $(\mathrm{A}-\mathrm{B})$ to $\mathrm{CDS}(\mathrm{B}-\mathrm{C})$. The sample is reported to become unstable at point C. (b) Axial strain against pressure: there is a clear inflection point at C. (c) Volumetric strain against pressure: there is a clear inflection point at $\mathrm{C}$. (d) Hardening modulus evolution as a function of pressure. The onset of instability is marked by $\boldsymbol{H}=\mathbf{0}$ at point $\mathbf{C}^{\prime}$

more experiments would afford a better calibration of the dilatancy function of the material.

The third major point of this section is that the onset of drained instabilities may not coincide with the onset of undrained instabilities such as static liquefaction. Fig. 7 shows a comparison of undrained triaxial compression simulations for the relatively loose sample of Changi sand studied in the previous section. The CDS results for the experiment and simulation are also reproduced in the figure for comparison. Three undrained triaxial compression numerical tests are performed on identical samples of sand with the same material conditions as those used for the loose sample with $e_{0}=0.95$. The only difference among the three undrained simulations was the initial confining pressures. The stress paths obtained, and shown in Fig. 7, display typical contractive behaviour, and undergo static liquefaction instability as described in Andrade (2009). It can be shown that, under undrained triaxial compression, the peak of the deviatoric stress (marked by the star symbol) signifies the onset of undrained instability or static liquefaction. Connecting the points at the onset of undrained instability in all three samples, one can define the so-called Lade's instability line (IL). From Fig. 7 it is very clear that the onset of drained instability for this same sample, and signalled by point $\mathrm{C}$ (or $\mathrm{C}^{\prime}$ for the simulation), is well above the IL. In fact, drained instability occurs in a zone between the instability line and the CSL. The reason for this is that, in general, the kinematic constraint in the undrained condition makes it impossible to have the appropriate strain mode (cf. equation (6)). It can be shown that the strain mode for undrained instability is one of pure shear, without any dilatancy components.

\section{CONCLUSION}

The objective of this paper was to shed some light into the mechanics of drained diffuse instabilities, from a theoretical perspective. A criterion has been presented, based on bifurcation analysis and elasto-plasticity theory, for the onset of diffuse instabilities. Exploiting the emerging strain increment mode, it has been possible to contrast drained diffuse instability with some of its close relatives: shear bands and static liquefaction. The framework introduced was applied to the specific case of Changi sand experiments under drained constant shear, where drained instabilities were reported in the laboratory for relatively loose and relatively dense sands. It has been shown that the proposed instability criterion explains and predicts the experimental observations. Beyond theoretical contributions to the understanding of the mechanics of instabilities in sands, this paper could contribute to understanding slope instabilities reported in case studies in the field, where fully drained conditions have been reported but could not be accounted for from a mechanics perspective. 


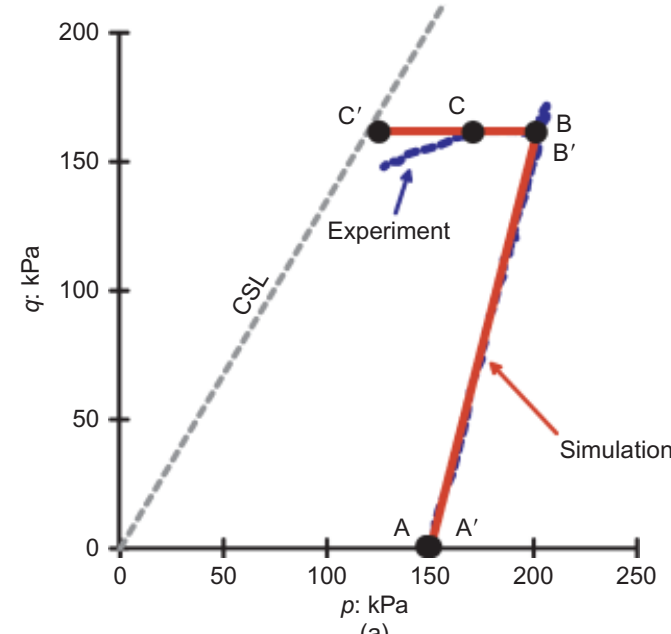

(a)

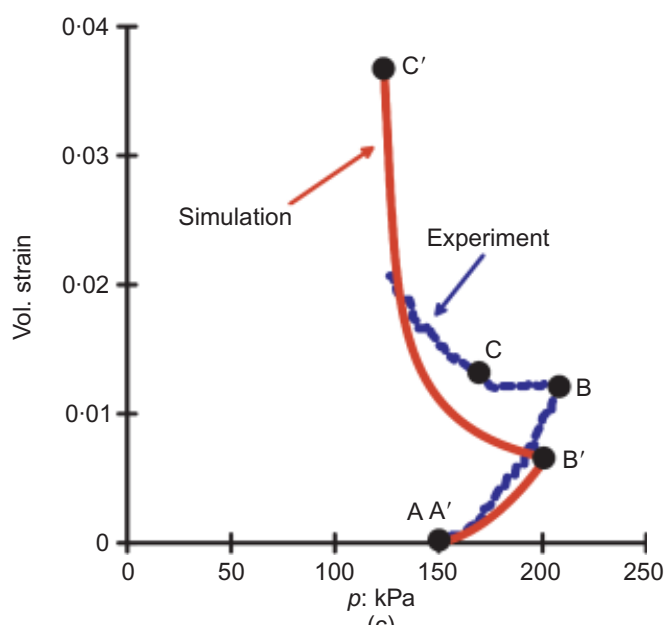

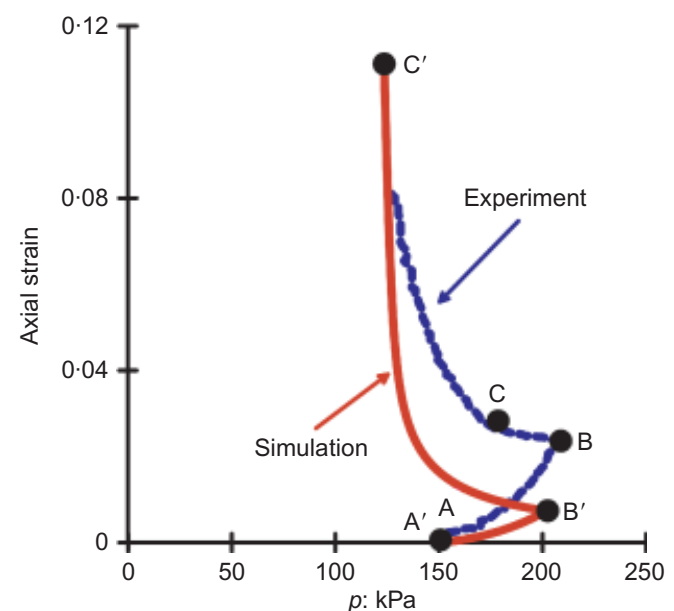

(b)

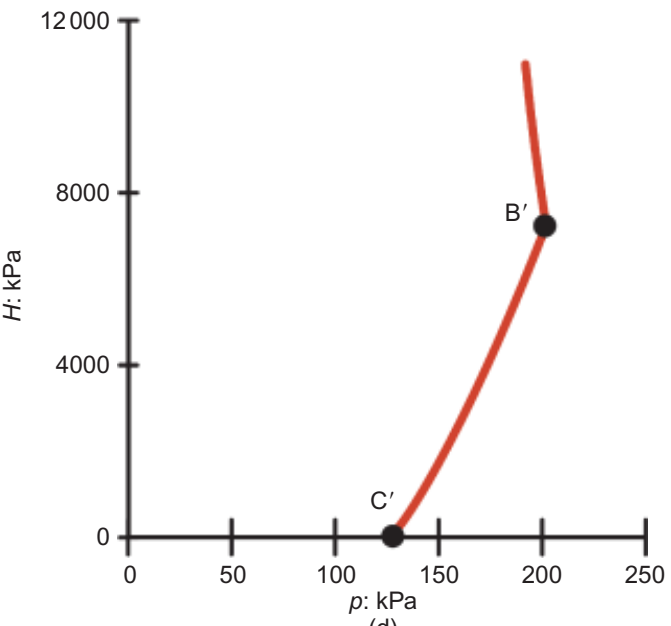

(d)

Fig. 5. Experimental and numerical results for relatively loose sample with $e_{0} \approx 0.95$. (a) Stress path marking transition from triaxial compression (A-B) to CDS (B-C). The sample is reported to become unstable at point C. (b) Axial strain against pressure: there is a clear inflection point at $\mathrm{C}$. (c) Volumetric strain against pressure: there is a clear inflection point at $\mathrm{C}$. (d) Hardening modulus evolution as a function of pressure. The onset of instability is marked by $\boldsymbol{H}=\mathbf{0}$ at point $\mathrm{C}^{\prime}$

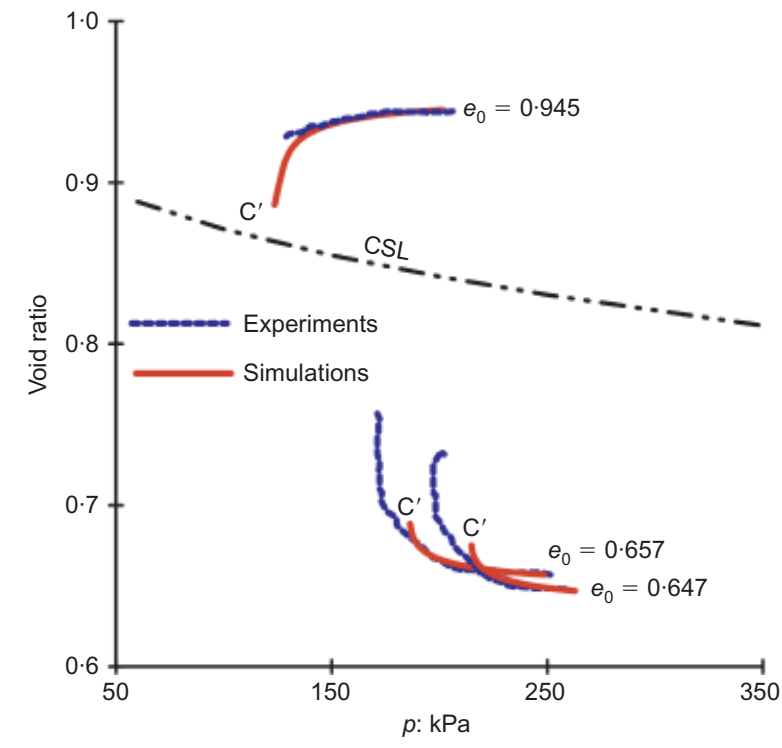

Fig. 6. Void ratio evolution for relatively dense samples and relatively loose sample as a function of mean pressure. Clearly, dense samples display a dilative tendency, whereas the loose sample shows contractive behaviour. The model overpredicts the material dilation and underpredicts its contractiveness. This may be the result of an inadequate calibration of the dilation function

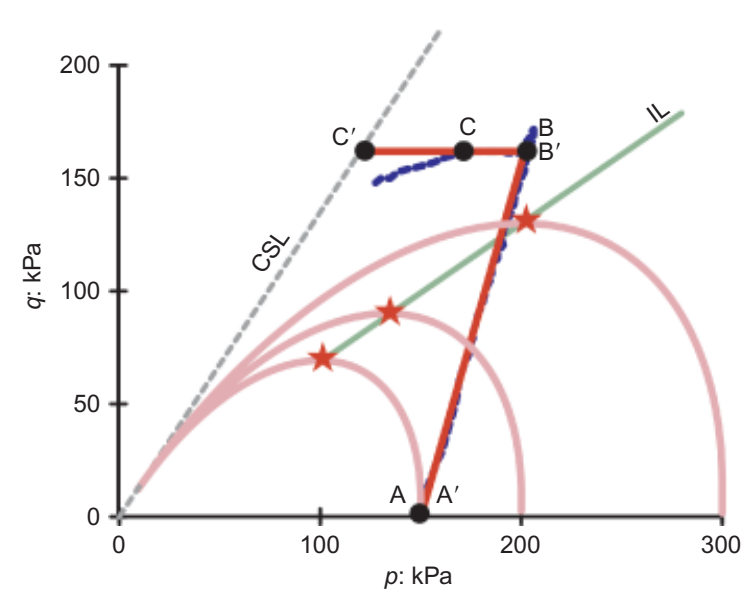

Fig. 7. Comparison between CDS and undrained stress paths (curves) for relatively loose sample of Changi sand. The peak values obtained by undrained compression paths correspond to liquefaction instabilities, and are used to define the instability line (IL). It is clearly shown that the obtained drained instability during the CDS path for the loose sample is well above the IL and before the CSL 


\section{ACKNOWLEDGEMENTS}

AMR acknowledges the partial financial support for the development of this work of Colciencias-Icetex and CEiBA. Support for JEA's work was partially provided by NSF grant number CMMI-1060087, AFOSR grant number FA9550-111-0052 and DOE grant number DE-FG02-08ER15980. This support is gratefully acknowledged.

\section{NOTATION}

$A_{0}$ material constant in Dafalias-Manzari model

$A_{\mathrm{d}}$ positive scaling function of dilatancy

c constitutive tangent

$c_{\mathrm{h}}$ material constant in Dafalias-Manzari model

$e$ current void ratio

$e_{\mathrm{c}} \quad$ void ratio on critical state line

$e_{0}$ initial void ratio

$e_{\mathrm{c} 0}$ critical state line material constant

$F$ yield surface

$G$ shear modulus

$G_{0} \quad$ elastic shear modulus

$H$ hardening modulus

$H_{\mathrm{L}}$ hardening modulus at onset of static liquefaction

$H_{\mathrm{sb}}$ hardening modulus at onset of shear band

$h$ positive state variable in Dafalias-Manzari model

$h_{0}$ material constant in Dafalias-Manzari model

$K$ bulk modulus

$M$ critical stress ratio

$M_{\mathrm{b}}$ bounding stress ratio

$M^{\mathrm{d}}$ dilatancy stress ratio

$m$ material constant in Dafalias-Manzari model

$n^{\mathrm{b}}$ material constant in Dafalias-Manzari model

$n^{\mathrm{d}}$ material constant in Dafalias-Manzari model

$p$ volumetric stress

$\dot{p}$ volumetric stress rate

$p_{\text {at }}$ atmospheric pressure

$Q$ plastic potential

$q$ deviatoric stress

$\dot{q}$ deviatoric stress rate

$z$ fabric dilatancy factor

$z_{\max }$ material constant in Dafalias-Manzari model

$\alpha$ back stress ratio

$\dot{\alpha}$ evolution law for back stress

$\beta$ dilatancy

$\dot{\varepsilon}$ strain vector increment

$\dot{\varepsilon}_{\mathrm{a}}$ axial strain rate

$\dot{\varepsilon}_{\mathrm{r}}$ radial strain rate

$\dot{\varepsilon}_{\mathrm{s}}$ total deviatoric strain rate

$\dot{\varepsilon}_{\mathrm{s}}^{\mathrm{e}}$ elastic deviatoric strain rate

$\dot{\varepsilon}_{\mathrm{s}}^{\mathrm{p}}$ plastic deviatoric strain rate

$\dot{\varepsilon}_{\mathrm{v}}$ total volumetric strain rate

$\dot{\varepsilon}_{\mathrm{v}}^{\mathrm{e}}$ elastic volumetric strain rate

$\dot{\varepsilon}_{\mathrm{v}}^{\mathrm{p}}$ plastic volumetric strain rate

$\eta$ stress ratio

$\eta_{\text {in }}$ initial value of $\eta$ at initiation of a new loading process

$\dot{\lambda}$ plastic multiplier

$\lambda_{\mathrm{c}}$ critical state line material constant

$v$ Poisson's ratio

$\xi$ critical state line material constant

$\dot{\sigma} \quad$ stress increment

$\sigma_{\mathrm{a}}$ axial stress

$\sigma_{\mathrm{r}}$ radial stress

$\psi \quad$ state parameter

\section{REFERENCES}

Andrade, J. E. (2009). A predictive framework for liquefaction instability. Géotechnique 59, No 8, 673-682, http://dx.doi.org/ 10.1680/geot.7.00087.

Andrade, J. E. \& Borja, R. I. (2006). Capturing strain localization in dense sands with random density. Int. J. Numer. Methods Engng 67, No. 11, 1531-1564.
Andrade, J. E. \& Ellison, K. C. (2008). Evaluation of a predictive constitutive model for sands. J. Geotech. Geoenviron. Engng 134, No. 12, 1825-1828.

Been, K. \& Jefferies, M. G. (1985). A state parameter for sands. Géotechnique 35, No. 2, 99-112, http://dx.doi.org/10.1680/ geot.1985.35.2.99.

Borja, R. I. (2006). Condition for liquefaction instability in fluidsaturated granular soils. Acta Geotech. 1, No 4, 211-224.

Chu, J. \& Wanatowski, D. (2008). Instability conditions of loose sand in plane strain. J. Geotech. Geoenviron. Engng 134, No 1, 136-142.

Chu, J., Leroueil, S. \& Leong, W. K. (2003). Unstable behaviour of sand and its implications for slope instability. Can. Geotech. J. 40, No. 5, 873-885.

Dafalias, Y. F. \& Manzari, M. T. (2004). Simple plasticity sand model accounting for fabric change effects. J. Engng Mech. 130, No 6, 622-633.

Darve, F. \& Laouafa, F. (2000). Instabilities in granular materials and application to landslides. Mech. Cohesive-Frictional Mater. 5, No 8, 627-652.

Gajo, A. (2004). The influence of system compliance on collapse of triaxial sand samples. Can. Geotech. J. 41, No. 2, 257-273.

Gajo, A., Piffer, L. \& De Polo, F. (2000). Analysis of certain factors affecting the unstable behaviour of saturated loose sand. Mech. Cohesive-Frictional Mater. 5, No 3, 215-237.

Hill, R. (1958). A general theory of uniqueness and stability in elastic-plastic solids. J. Mech. Phys. Solids 6, No 3, 236-249.

Imposimato, S. \& Nova, R. (1998). An investigation on the uniqueness of the incremental response of elastoplastic models for virgin sand. Mech. Cohesive-Frictional Mater. 3, No. 1, 65-87.

Jefferies, M. G. (1993). Nor-Sand: a simple critical state model for sand. Géotechnique 43, No. 1, 91-103, http://dx.doi.org/ 10.1680/geot.1993.43.1.91.

Lade, P. V. (1992). Static instability and liquefaction of loose fine sandy slopes. J. Geotech. Engng 118, No. 1, 51-71.

Lade, P. V. (1993). Initiation of static instability in the submarine Nerlerk berm. Can. Geotech. J. 30, No. 6, 895-904.

Lade, P. V. \& Pradel, D. (1990). Instability and plastic flow of soils. I: Experimental observations. J. Engng Mech. 116, No. 2532, 2535-2550.

Li, X. S. \& Wang, Y. (1998). Linear representation of steady-state line for sand. J. Geotech. Geoenviron. Engng 124, No 12, $1215-1217$.

Lindenberg, J. \& Koning, H. L. (1981). Critical density of sand. Géotechnique 31, No. 2, 231-245, http://dx.doi.org/10.1680/ geot.1981.31.2.231.

Manzari, M. T. \& Dafalias, Y. F. (1997). A critical state two-surface plasticity model for sands. Géotechnique 47, No 2, 255-272, http://dx.doi.org/10.1680/geot.1997.47.2.255.

Nova, R. (1994). Controllability of the incremental response of soil specimens subjected to arbitrary loading programmes. J. Mech. Behav. Mater. 5, No. 2, 193-201.

Olson, S. M., Stark, T. D., Walton, W. H. \& Castro, G. (2000). 1907 static liquefaction flow failure of the north dike of Wachusett dam. J. Geotech. Geoenviron. Engng 126, No. 1184, 1184-1193.

Ramos, A. M. \& Lizcano, A. (2010). Strain localization by mean of the bifurcation theory applied to a hypoplastic constitutive model. Proceedings of Geoflorida. Advances in analysis, modeling and design, West Palm Beach, FL, http://dx.doi.org/10.1061/ 41095(365)41.

Rudnicki, J. W. \& Rice, J. R. (1975). Conditions for localization of deformation in pressure-sensitive dilatant materials. J. Mech. Phys. Solids 23, No. 6, 371-394.

Schofield, A. \& Wroth, P. (1968). Critical state soil mechanics. New York: McGraw-Hill.

Skopek, P., Morgenstern, N., Robertson, P. \& Sego, D. (1994). Collapse of dry sand. Can. Geotech. J. 31, No. 6, 10081014.

Vaid, Y. P. \& Chern, J. C. (1983). Effect of static shear on resistance to liquefaction. Soils Found. 23, No. 1, 47-60.

Wanatowski, D. \& Chu, J. (2007). Static liquefaction of sand in plane strain. Can. Geotech. J. 44, No. 3, 299-313. 